Address for correspondence: Jun Zhang, Department of Clinical Laboratory Medicine, Shanghai Public Health Clinical Center, Fudan University, 2901 Caolang Rd, Jinshan District, Shanghai, China; email: zhangjun@shaphc.org

\section{Human Deaths and Third-Generation Cephalosporin use in Poultry, Europe}

To the Editor: Globally, antimicrobial drug resistance is rapidly rising, with resultant increased illness and death. Of particular concern is Escherichia coli, the most common bacterium to cause invasive disease in humans (1). In Europe, increasing proportions of bloodstream infections caused by $E$. coli are resistant to thirdgeneration cephalosporins $(1,2)$.

Resistant E. coli can be transmitted to humans from animals. A large proportion of resistant isolates causing human infections are derived from food animals (3-6). However, lack of data has made it difficult to quantify the proportion of antimicrobial drug resistant E. coli infecting persons through food sources and the resultant effects on human health. Recent data from the Netherlands now make such estimates possible $(2,6)$. The additional illness and death among humans resulting from bloodstream infections caused by third-generation cephalosporin-resistant $E$. coli (G3CREC) has been calculated for Europe (2). In the Netherlands, there were 205 G3CREC cases during 2007 (4\% of all E. coli bloodstream infections) (2). Another study in the Netherlands revealed that $56 \%$ of the resistance genes in G3CREC in humans were identical to genes derived from $E$. coli isolated from retail chicken samples (6). Using the findings of Overdevest et al. (6) and de Kraker et al. (2), we calculated that, in the Netherlands, infections in humans with G3CREC derived from poultry sources were associated with 21 additional deaths. G3CREC-related illness also resulted in 908 hospital bed-days needed to treat persons with these antimicrobial drug resistant bloodstream infections. If these values were extrapolated to all of Europe (i.e., if $56 \%$ of G3CREC were derived from poultry), 1,518 additional deaths and an associated increase of 67,236 days of hospital admissions would be counted as a result of cephalosporin and other antimicrobial drug use in poultry.

To more accurately estimate the associated increased deaths among persons resulting from third-generation cephalosporin use in poultry, detailed data from more countries is essential. Needed data include records of antimicrobial drug use and resistant bacterial strains found in food animals and domestic and imported foods. However, we already know that G3CREC is rapidly rising in many countries, and in Europe, the infection rate is likely to have tripled from 2007 to 2012 (2). Globally, billions of chickens receive third-generation cephalosporins in ovo or as day-old chicks to treat E. coli infection, a practice that has resulted in large reservoirs of resistant bacteria. In Canada, this practice has been associated with substantial increases in resistance to third-generation cephalosporins in Salmonella enterica serovar Heidelberg isolates detected in humans. (7). The United States Food and Drug Administration recently prohibited the off-label use of cephalosporins, including prophylactic uses, in major food animal species, including poultry $(8)$.

The number of avoidable deaths and the costs of health care potentially caused by third-generation cephalosporin use in food animals is staggering. Considering those factors, the ongoing use of these antimicrobial drugs in mass therapy and prophylaxis should be urgently examined and stopped, particularly in poultry, not only in Europe, but worldwide.

\section{Peter Collignon, Frank M. Aarestrup, Rebecca Irwin, and Scott McEwen}

Author affiliations: The Canberra Hospital, Garran, Canberra, Australian Capital Territory, Australia (P. Collignon); Australian National University, Woden, Australian Capital Territory, Australia (P. Collignon); EU Reference Laboratory for Antimicrobial Resistance. Copenhagen, Denmark (F.M. Aarestrup); World Health Organization Collaborating Centre for Antimicrobial Resistance in Foodborne Pathogens, Copenhagen (F.M. Aarestrup); Public Health Agency of Canada. Guelph, Ontario, Canada (R. Irwin); and Ontario Veterinary College/University of Guelph, Guelph (S. McEwen)

DOI: http://dx.doi.org/10.3201/eid1908.120681

\section{References}

1. European Centre for Disease Prevention and Control. Antimicrobial resistance surveillance in Europe 2010. Annual report of the European Antimicrobial Resistance Surveillance Network (EARSNet). Stockholm: The Centre; 2011.

2. de Kraker ME, Davey PG, Grundmann H; BURDEN study group. Mortality and hospital stay associated with resistant Staphylococcus aureus and Escherichia coli bacteremia: estimating the burden of antibiotic resistance in Europe. PLoS Med. 2011;8:e1001104. Epub 2011 Oct 11. http://dx.doi.org/10.1371/journal. pmed.1001104

3. Jakobsen L, Spangholm DJ, Pedersen $\mathrm{K}$, Jensen LB, Emborg HD, Agersø Y, et al. Broiler chickens, broiler chicken meat, pigs and pork as sources of ExPEC related virulence genes and resistance in Escherichia coli isolates from community-dwelling humans and UTI patients. Int J Food Microbiol. 2010;142:264-72. http://dx.doi.org/10.1016/j.ijfoodmicro.2010.06.025

4. Vieira AR, Collignon $\mathrm{P}$, Aarestrup FM, McEwen SA, Hendriksen RS, Hald T, et al. Association between antimicrobial resistance in Escherichia coli isolates from food animals and blood stream isolates from humans in Europe: an ecological study. Foodborne Pathog Dis. 2011;8:1295-301. http://dx.doi. org/10.1089/fpd.2011.0950

5. Johnson JR, Sannes MR, Croy C, Johnston B, Clabots C, Kuskowski MA, et al. Antimicrobial drug-resistant Escherichia coli from humans and poultry 
products, Minnesota and Wisconsin, 20022004. Emerg Infect Dis. 2007;13:838-46. http://dx.doi.org/10.3201/eid1306.061576

6. Overdevest I, Willemsen I, Rijnsburger $\mathrm{M}$, Eustace A, Xu L, Hawkey P, et al. Extended-spectrum $\beta$-lactamase genes of Escherichia coli in chicken meat and humans, the Netherlands. Emerg Infect Dis. 2011;17:1216-22. http://dx.doi.org/ 10.3201/eid1707.110209

7. Dutil L, Irwin R, Finley R, Ng LK, Avery B, Boerlin P, et al. Ceftiofur resistance in Salmonella enterica serovar Heidelberg from chicken meat and humans, Canada. Emerg Infect Dis. 2010;16:48-54. http://dx.doi.org/10.3201/eid1601.090729

8. US Food and Drug Administration. Cephalosporin order of prohibition goes into effect. April 6, 2012 [cited 2012 Apr 20]. http://www.fda.gov/AnimalVeterinary/NewsEvents/CVMUpdates/ ucm299054.htm

Address for correspondence: Peter Collignon, Infectious Diseases and Microbiology, Canberra Hospital, PO Box 11, Woden. ACT 2607, Australia; email: peter.collignon@act.gov.au

\section{Autochthonous Human Schistosomiasis, Malaysia}

To the Editor: In Malaysia, the only histologically diagnosed autochthonous cases of human schistosomiasis were reported in the 1970s, all in rural aborigine (Orang Asli) populations (1-3) (online Technical Appendix Figure 1, wwwnc.cdc.gov/EID/ article/19/8/12-1710-Techapp1.pdf). The fact that the infection had been found only among aborigines had led to the proposal of a distinct unknown schistosome with an animal reservoir causing sylvatic infections $(2,3)$. Consequently, during the 1980s, Schistosoma malayensis $\mathrm{n}$. $\mathrm{sp}$. was described from intermediate snail (Robertsiella sp.) and final mammalian hosts (Rattus muelleri and $R$. tiomanicus [4]). $S$. malayensis is closely related to $S$. mekongi and differs genetically from the latter by $\approx 10 \%$. Both species differ from $S$. japonicum by $25 \%(5)$, and adult and ova morphologies are similar (4). Few transmission sites for this new $S$. japonicum-complex schistosome species were identified in rural areas (4). We report after 30 years the histologic finding of $S$. malayensislike eggs in the liver of a Malay man and discuss public health implications.

A 29-year-old male nonaboriginal Malay from Subang Jaya in Selangor State, Peninsular Malaysia, had died suddenly of an intoxication in 2011. According to his mother, he had reported hematuria and dysuria during adolescence. Similar symptoms had reoccurred 10 years later, accompanied by constipation. The patient had never been outside of Malaysia, and he had gone bomb fishing for many years in Sungai Lepar Utara, a river near his village (Felda Tekam Utara, Jerantut, Pahang; 3'52'30'N, $\left.102^{\circ} 49^{\prime} 2^{\prime \prime} \mathrm{E}\right)$. No tests on blood or feces were performed before his death. An autopsy was conducted in Sungai Buloh Hospital, and gross pathology showed a normal heart, kidneys, and brain. The lungs were edematous and congested. The liver also was congested, but no macroscopic lesions were seen. Toxicology investigations showed methadone and a derivative in his blood and urine. During a routine histologic examination, several granulomas with intensive lymphocyte, monocyte, and eosinophil infiltration surrounding clusters of ovoidal eggs were found in the liver (Figure; online Technical Appendix Figure 2). Serial sectioning showed that the eggs contained miracidia and had the overall appearance of $S$. malayensis-like ova $50 \mu \mathrm{m}$ long $\times 28 \mu \mathrm{m}$ wide. The ova were not operculated and had no bipolar plugs; the thin yellowish shell was not striated, but a knob-like structure was seen laterally. Morphologic differential diagnoses included eggs of Capillaria hepatica (bipolar striated ova in liver), Dicrocoelium (slightly smaller operculated ova typically found in feces or bile), and the similar Eurytrema (thick-walled operculated ova in feces).

Schistosomiasis is endemic in many developing countries and infects $>207$ million persons living in rural agricultural areas (6). In Asia, S. japonicum, S. mekongi, and S. malayensis cause human infection (7), with $S$. japonicum being the most dangerous. In Malaysia, S. malayensis, in addition to $S$. spindale, $S$. nasale, S. incognitum, Trichobilhazia brevis, and Pseudobilharziella lonchurae, is known to occur in wildlife (8). The first known case of human schistosomiasis in Malaysia was discovered in 1973 during an autopsy of an aborigine. Schistosoma eggs resembling those of $S$. japonicum were found in liver tissue (1). A subsequent retrospective autopsy study revealed additional cases with these Schistosoma japonicum-like ova in the rural aboriginal population, resulting in an overall prevalence of $3.9 \%$ (2). Several attempts to recover eggs from feces from the Orang Asli population in peninsular Malaysia (3), a biopsy-positive Orang Asli (3), and serologically positive persons (9, and others) were unsuccessful, however, which was attributed to the zoonotic nature of $S$. malayensis and thus missing adaptation to the human host. Whether hematuria, a typical sign of S. haematobium infection, as seen in the patient reported here also was caused by $S$. malayensis disease remains unclear because symptoms of the latter have not been reported. Serologic surveys for schistosomiasis in peninsular Malaysia showed prevalences of $4 \%-25 \%$ in selected rural populations (9). Because infected Robertsiella snails had been found almost exclusively in small rivers (4,9-habitats like the Sungai Lepar Utara River in our current report-we suspect that the patient most likely became infected while fishing. The travel history may not be accurate 